\title{
SECAGEM DE EXTRATOS DE ERVA-MATE EM SECADOR POR ATOMIZAÇÃO ${ }^{1}$
}

\author{
Alice Teresa VALDUGA ${ }^{2,3, *}$, Vania BATTESTIN ${ }^{2}$, José Roberto Delalibera FINZER ${ }^{2,3,4}$
}

\section{RESUMO}

Efetuou-se a extração de solúveis de erva-mate, progênie Cambona 4, utilizando extrator com percolação de solvente (água). O extrato obtido apresentou uma concentração de sólidos de aproximadamente $3 \%$. Ao extrato foi adicionada goma arábica nas concentrações de $0 ; 0,2 ; 0,4 ; 0,6 ; 0,8 ; 1,0 ; 1,5$ e 2,0\%, em relação aos sólidos contidos no mesmo. As misturas foram efetuadas com o objetivo de estudar a influência da goma arábica na secagem e no sabor das bebidas. Os extratos foram processados em secador por atomização nas condições operacionais médias: temperatura e vazão do ar: $190^{\circ} \mathrm{C}$ e $32,1 \mathrm{~m}^{3} / \mathrm{h}$; alimentação de extrato $340 \mathrm{~mL} / \mathrm{h}$. Os conteúdos de umidade do pó obtido variaram de 1,8 a 6,6\%(bu). Efetuou-se análise sensorial de três formulações com concentrações: 0; 0,2 e 1,0\%. Aos resultados experimentais aplicou-se tratamento estatístico e verificou-se maior preferência pela formulação contendo $0,2 \%$ de ervamate, o que mostrou a influência do agente encapsulante na retenção de aromas.

Palavras-chave: erva-mate; extração de solúveis; secagem por atomização; encapsulamento; análise sensorial.

\section{SUMMARY}

DRYING OF MATÉ EXTRACT IN SPRAY DRYER. It was effected extraction of soluble of mate, lineage Cambona 4, using extracting, with percolating of solvent (water). The gotten extract presented a $3 \%$ solid concentration. The extract was used for formularization of mixtures with arabica gum in the concentrations of $0 ; 0.2 ; 0.4 ; 0.6 ; 0.8 ; 1.0 ; 1.5$ and $2.0 \%$, in relation to solids contained in the extract. The formularizations had been effected with the objective to study the volatile and aromatics substance clamping. The extracts had been processed in spray dryer in the average operational conditions: temperature and tax of air: $190^{\circ} \mathrm{C}$ and $32.1 \mathrm{~m}^{3} / \mathrm{h}$; extract feed of $340 \mathrm{~mL} / \mathrm{h}$. The contents of humidity of the gotten dust had varied of 1.8 to $6.6 \%(\mathrm{db})$. Sensorial analysis of three formularizations with concentrations was carried out: $0 ; 0.2$ and $1.0 \%$. A statistical analysis were carried out to experimental results and was verified bigger preference for the formularization contends $0,2 \%$ of gum arabic, what it showed the influence of the encapsulating agent in the clamping of flavor.

Keywords: mate; soluble extraction; spray drying; encapsulation; sensorial analysis.

\section{1 - INTRODUÇÃO}

Secadores por atomização são usados na secagem de soluções, suspensões, emulsões, polpas e pastas no processamento de alimentos [5]. No encapsulamento de aromas, em termos de volume de produção, nos processos industriais são utilizados: extrusão, atomização e leito fluidizado $[6,10]$. No processamento de menores quantidades de produtos são utilizadas técnicas como: liofilização; encapsulação de óleos e graxas; e adsorção [9].

A matéria-prima orgânica e geneticamente homogênea que foi utilizada nesta pesquisa consiste em uma variedade da espécie Ilex. paraguariensis St.Hil, a qual foi atribuída a denominação Progênie Cambona 4, pela equipe do Projeto Sistemas Agroflorestais da EMBRAPAFloresta (Colombo-PR).

A denominação de erva-mate orgânica, refere-se ao fato de que no sistema de produção da erva-mate não se utiliza qualquer produto químico, sendo totalmente natural. Não são empregados inseticidas nem adubos quimicos, apenas adubos orgânicos naturais, como: esterco, húmus de minhoca, cama de aviários [4].

\footnotetext{
Recebido para publicação em 07/08/2001. Aceito para publicação em 03/12/2002 (000706).

2. Curso de Engenharia de Alimentos da Universidade Regional Integrada do Alto Uruguai e Missões - Campus de Erechim - URICER - Av. Sete de Setembro 1621 -Erechim - RS.E-mail:valice@uricer.edu.br

${ }^{3} U F$ SCAr-PGERN, São Carlos - SP

${ }^{4} U F U-F E Q U I$, Uberlândia- $M G$

* A quem a correspondência deve ser enviada.
}

O Relatório de impacto ambiental, da Barragem de Machadinho, evidenciou que deve-se plantar 1,5 milhões de mudas de árvores, compensatório do que foi inundado pela barragem. A Secretaria do Meio Ambiente do Rio Grande do Sul, que fiscaliza a reposição, autorizou o repovoamento com erva-mate da variedade progênie Cambona 4 em uma área de 105 hectares [3, 4].

Já existe cultivo com 4 anos, da variedade Cambona 4 (em outra área), a qual foi utilizada na realização de testes de processamento no trabalho atual. Com relação à produção esperada, em 4 anos, do reflorestamento terse-á a produção de 20 toneladas/ano de erva-mate orgânica cancheada, o que consiste no material seco e triturado [4].

O trabalho atual é parte de um estudo mais amplo e direcionado para dar subsídios à manutenção do homem no campo, através do desenvolvimento de tecnologias alternativas [13] no processamento de erva mate. A matéria-prima foi processada com a utilização de: sapeco [7]; secador de bandejas vibradas [8], dispositivos de extração de solúveis de erva-mate [1, 12]; concentração do extrato, seguindo a secagem do material em secador por atomização ("spray dryer"), o que consiste na abordagem deste trabalho e por liofilização [2]. Efetuou-se a secagem de extratos de erva-mate por atomização utilizando como agente encapsulante goma arábica em diversas concentrações, para utilizar o produto na preparação de bebidas e produtos alimentícios. A goma arábica (goma acácia), consiste em uma exudação da casca da árvore acácia espinhosa que se desenvolve próximo ao deserto de Saara. A goma arábica é utilizada para 
fins alimentícios e farmacêuticos [14]. A goma arábica evita a cristalização do açúcar nos produtos de confeitaria, estabiliza as emulsões e contribui no aumento da viscosidade. Nos produtos de confeitaria evita a absorção excessiva de umidade dos recheios e de coberturas. A goma arábica é um útil fixador de aromas em misturas desidratadas para bebidas. Nas bebidas esta goma funciona como estabilizante de emulsões e espumas [15]. O objetivo deste trabalho foi o estudo da secagem de extrato de erva-mate em secador por atomização, verificando a influência de goma arábica na secagem e nas características sensoriais da bebida.

\section{2 - MATERIAIS E MÉTODOS}

Umidade de $61,9 \%$ (bu), proveniente do municipio de Machadinho-RS, foi processada no mês de janeiro de 2001, na Indústria Camol localizada no mesmo município, até a etapa de secagem e de pré-moagem. O conteúdo de umidade do material seco e pré-triturado foi determinada em estufa Fanem à temperatura de $105^{\circ} \mathrm{C}$ até massa constante, obtendo-se de 8,17\% (bu). O material foi triturado utilizando um equipamento Max-mister Walita.

A extração de solúveis de erva-mate foi efetuada com um extrator por percolação de solvente (Bialetti), ver a Figura 1, onde: A- depósito de solvente; B - filtro; C válvula de segurança; D coletor de extrato, E- filtro; Fborracha de vedação.

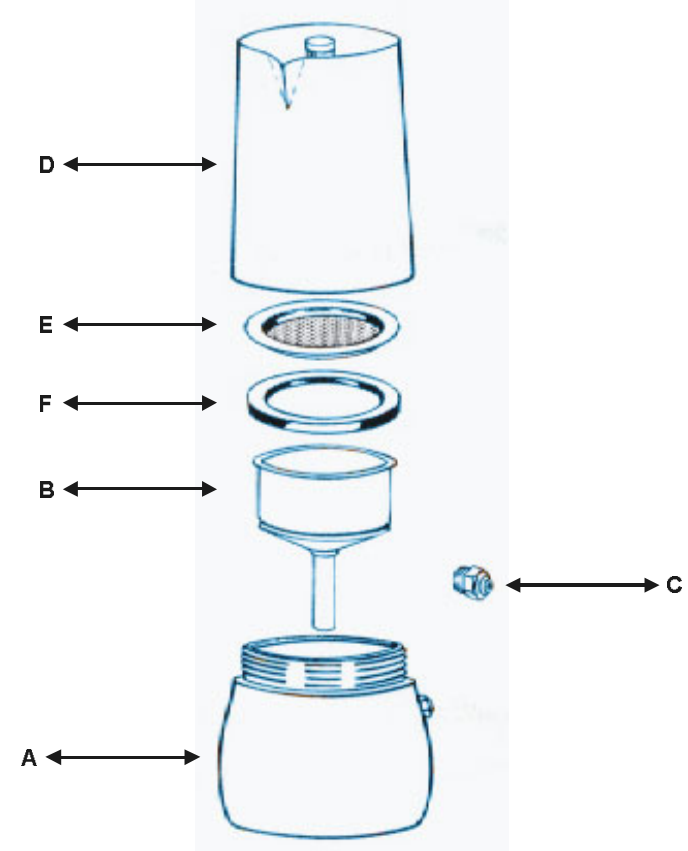

FIGURA 1. Extrator de solúveis por percolação de solvente

A secagem do extrato de erva foi efetuada em um secador por atomização (spray dryer) Lab Plant SD-05 (Figura 2).

Ensaio inicial de extração de solúveis da erva-mate, processando $24,029 \mathrm{~g}$ e utilizando $315,2 \mathrm{~g}$ de água como agente de extração (que consiste na água que percolou o leito de erva-mate), em um tempo de extração de 10 minutos, forneceu os seguintes resultados: temperatura do extrato descarregado no coletor (D na Figura 1 ), $93^{\circ} \mathrm{C}$; concentração de solidos no extrato de aproximadamente $3 \%$ em massa; solúveis extraídos, 79,91\%. A mesma técnica foi utilizada nas outras extrações efetuadas neste trabalho. A umidade dos sólidos residuais e das soluções foram determinados em estufa Fanem à temperatura de $105^{\circ} \mathrm{C}$ até massa constante.

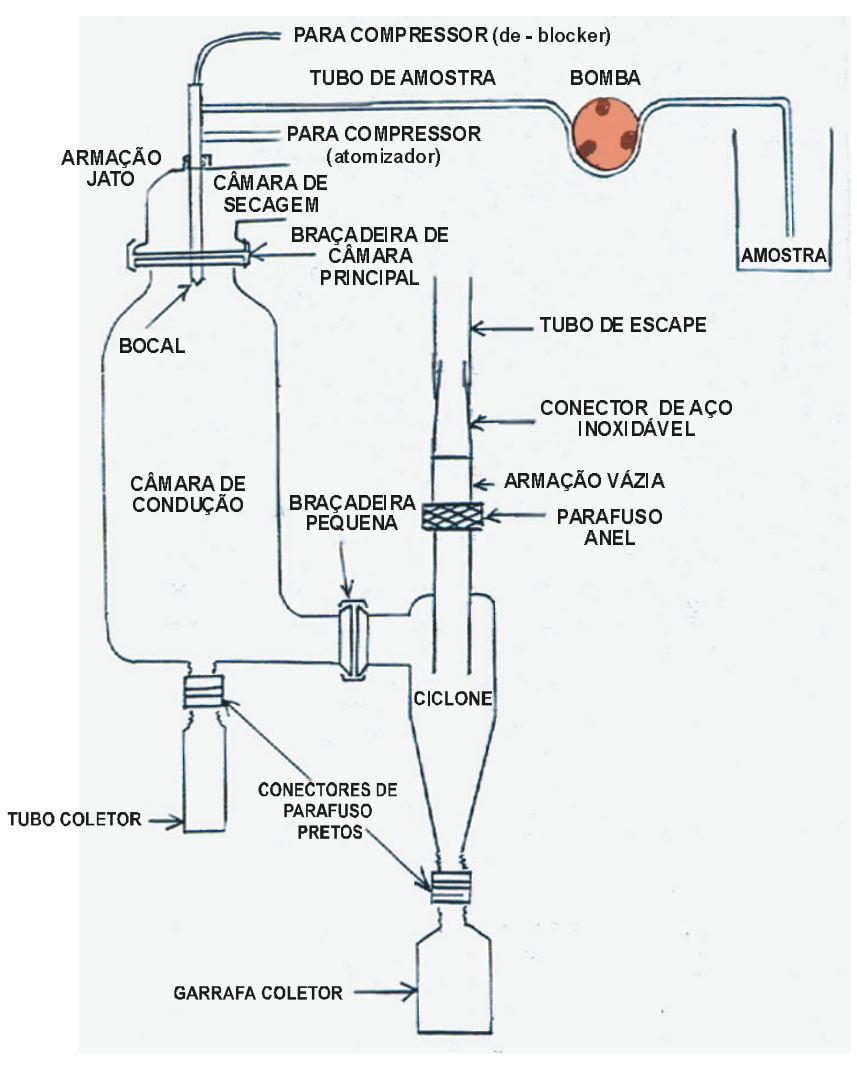

FIGURA 2. Esquema da instalação de secagem por atomização.

O encapsulamento para retenção das substâncias voláteis e flavorizantes da erva-mate, foi efetuado utilizando-se goma arábica nas concentrações de 0,2;0,4; 0,$6 ; 0,8 ; 1,0 ; 1,5$ e 2,0\% em relação aos sólidos contidos no extrato.

Na realização da análise sensorial foi utilizado o Teste de Ordenação e os resultados foram avaliados por meio da Interpretação de Fisher e do Teste de Tukey.

\section{3 - RESULTADOS E DISCUSSÃO}

\section{1 - Processamento de extrato de erva-mate sem aditivo}

Utilizou-se o extrator (Bialetti) na lixiviação dos solúveis. Efetuaram-se quatro extrações utilizando-se cerca de 24 gramas de erva-mate em cada extração. Em cada extração foram adicionadas $350 \mathrm{~g}$ de água. no depósito de 
solvente (ver A na Figura 1). Após cada extração, parte da água não percolou o leito de erva-mate e permaneceu no depósito de solvente, o que é indicado na Tabela 1, juntamente com os resultados das extrações.

TABELA 1. Extração de solúveis de erva-mate (Cambona 4).

\begin{tabular}{ccccccc}
\hline Extração & $\begin{array}{c}\mathrm{M}_{0} \\
(\mathrm{~mL})\end{array}$ & $\begin{array}{c}\mathrm{M}_{1} \\
(\mathrm{~g})\end{array}$ & $\begin{array}{c}\mathrm{M}_{2} \\
(\mathrm{~g})\end{array}$ & $\begin{array}{c}\text { Tempe- } \\
\text { ratura } \\
\text { extrato }\left({ }^{\circ} \mathrm{C}\right)\end{array}$ & $\begin{array}{c}\text { Tempo } \\
\text { extração } \\
(\mathrm{min})\end{array}$ & $\begin{array}{c}\text { Resíduo } \\
\text { água } \\
\text { extrator }(\mathrm{g})\end{array}$ \\
1 & 350 & 24,1 & 219 & 98 & 7 & 79,5 \\
2 & 350 & 24,1 & 269 & 81 & 5 & 8,6 \\
3 & 350 & 24,2 & 280 & 80 & 5 & 7,3 \\
4 & 350 & 24,6 & 291 & 80 & 4 & 4,0 \\
\hline
\end{tabular}

$\mathrm{M}_{0}$, massa inicial de solvente; $\mathrm{M}_{1}$, massa amostra processada; $\mathrm{M}_{2}$, Massa extrato

Toda massa de extrato obtida foi misturada totalizando 1059g, sendo submetida a peneiramento, utilizando peneira da série Tyler de 115 malhas (diâmetro da abertura de $0,124 \mathrm{~mm}$ ) A umidade média do extrato obtido foi de $97,12 \%$. O extrato foi submetido a secagem no secador por atomização. As condições operacionais de secagem são indicadas na Tabela 2. O volume de extrato processado foi de $500 \mathrm{~mL}$ a uma vazão média de $340 \mathrm{~mL} / \mathrm{h}$.

TABELA 2. Condições operacionais do "Spray Dryer".

\begin{tabular}{cccccc}
\hline $\begin{array}{c}\text { Tempo } \\
(\min )\end{array}$ & $\begin{array}{c}\mathrm{T}_{0} \\
\left({ }^{\circ} \mathrm{C}\right)\end{array}$ & $\begin{array}{c}\mathrm{T}_{1} \\
\left({ }^{\circ} \mathrm{C}\right)\end{array}$ & $\begin{array}{c}\mathrm{P}_{0} \\
(\mathrm{bar})\end{array}$ & $\begin{array}{c}\text { Vazão de } \\
\mathrm{ar} \mathrm{m}^{3} / \mathrm{h}\end{array}$ & $\begin{array}{c}\text { Vazão média extrato } \\
\mathrm{mL} / \mathrm{h}\end{array}$ \\
\hline 0 & 190 & 102 & 0,7 & 32,1 & 340 \\
15 & 190 & 113 & 0,7 & 32,1 & 340 \\
30 & 190 & 114 & 0,7 & 32,1 & 340 \\
45 & 190 & 115 & 0,7 & 32,1 & 340 \\
60 & 190 & 114 & 0,7 & 32,1 & 340 \\
\hline
\end{tabular}

$\mathrm{T}_{0}$, temperatura de entrada do ar; $\mathrm{T}_{1}$, temperatura de saída do ar da câmara de secagem; $P_{0}$, pressão de entrada do ar de atomização

A umidade do pó obtido foi de $1,79 \%(\mathrm{bu})$ sendo a massa coletada de 4,21g. Como o total de sólidos existentes no extrato consistia de $14,54 \mathrm{~g}$, então a eficiência de coleta foi de $28,95 \%$.

\section{2 - Processamento de extrato de erva-mate com adição de goma arábica}

Novas extrações de solúveis de erva-mate, progênie Cambona 4 foram efetuadas. Os extratos tiveram adição de goma arábica com concentrações de 0,2;0,4; 0,6;0,8 e 1,0\% em relação ao conteúdo de sólidos total de sólidos. Os resultados da secagem processando $1000 \mathrm{~mL}$ do extrato para cada concentração de goma arábica são mostrados na Tabela 3. Em todos os experimentos foi possivel observar que o pó transferido para o ciclone, durante o processamento de secagem no "spray dryer", não se depositava no tubo coletor, ficando aderido nas paredes do ciclone. Com o aumento da concentração de goma arábica adicionada ao extrato, a quantidade de pó aderido à parede do ciclone aumentou. É provável que ocorra efeitos de adesão das partículas encapsuladas com a parede do ciclone. Em experimento realizado à temperatura do ar de secagem de $170^{\circ} \mathrm{C}$, observou-se que ocor- ria depósito de pó no tubo coletor situado na base inferior do ciclone. A adesão de pó mais acentuada na parede do ciclone, na temperatura de $190^{\circ} \mathrm{C}$, pode estar relacionada ao fenômeno da temperatura de transição vítrea. Isto acontece em secadores por atomização, quando se efetua o resfriamento da parede externa para diminuir a temperatura de transição vítrea e facilitar o escoamento dos sólidos.

TABELA 3. Processamento de erva-mate com goma arábica.

\begin{tabular}{ccc}
\hline $\mathrm{P}_{0}$ & $\mathrm{C}$ & $\mathrm{M}$ \\
$(\%)$ & $(\%)$ & $(\mathrm{g})$ \\
\hline 0 & 2,88 & 4,21 \\
0,2 & 2,80 & 11,49 \\
0,4 & 2,80 & 12,09 \\
0,6 & 2,91 & 13,80 \\
0,8 & 2,91 & 14,32 \\
1,0 & 2,91 & ----- \\
\hline
\end{tabular}

$\mathrm{P}$, percentagem de goma arábica: C, concentração de sólidos no extrato; M, massa dé pó coletado; $\mathrm{P}_{1}$, percentagem coleta de pó, $\mathrm{U}$, umidade do pó coletado (bu).

Na Figura 3 indica-se a quantidade de pó coletado em função das concentrações de goma arábica.

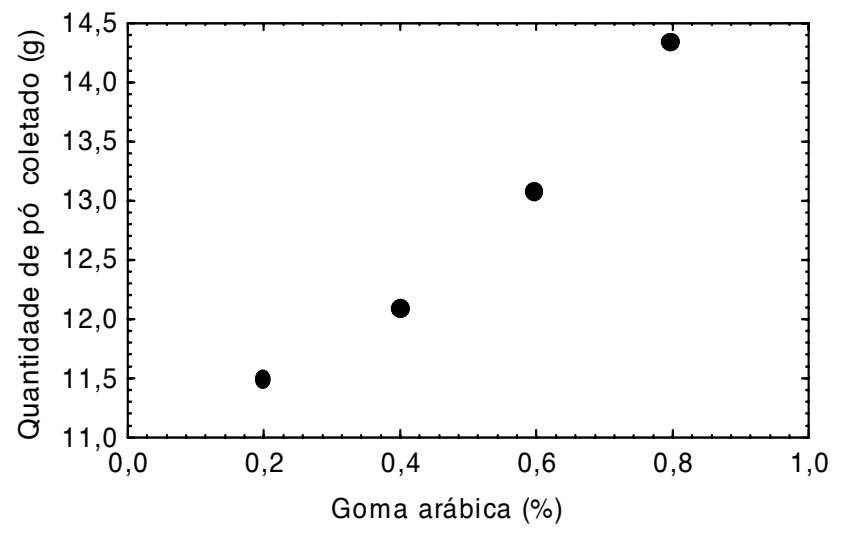

FIGURA 3. Massa de pó de erva-mate coletado.

Na Figura 4 indica-se a umidade de pó coletado em função das concentrações de goma arábica.

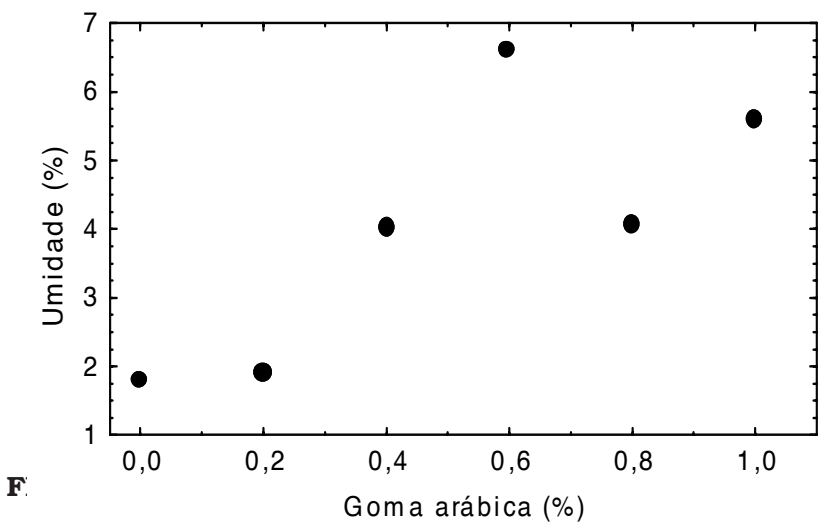

Quando a percentagem de goma arábica adicionada ao extrato varia de 0,2 para 0,8, a massa de pó coletada 
aumenta em cerca de $25 \%$. Assim, ao utilizar goma arábica na concentração de $0,8 \%$, para obter $1250 \mathrm{~kg}$ de pó, necessita-se 9,5kg de goma arábica. Convém observar que ao processar extratos com maior concentração de goma arábica, o pó obtido se torna mais úmido.

Além disso, a massa de pó coletado aumenta. Isto pode ser explicado por um aumento do tamanho das partículas formadas, pois a eficiência de coleta do ciclone aumenta com o aumento do tamanho das partículas, e maiores retém mais umidade para um mesmo tempo de secagem.

Após o término da secagem por atomização, o aquecimento do ar foi desligado e aguardou-se 10 minutos para ocorrer o resfriamento do equipamento. Na seqüência retirou-se o pó de erva-mate, o qual estava praticamente todo aderido à parede da câmara de secagem.

Para analisar a influência do tempo de resfriamento da câmara de secagem sobre a umidade do pó, foram efetuados novos experimentos, processando $500 \mathrm{~mL}$ de extrato para cada concentração de goma arábica. Nestes experimentos, o tempo de resfriamento da câmara situou-se no intervalo de tempo de 3 a 4 minutos. Após a interrupção do aquecimento do ar, o mesmo continuava a escoar em temperatura superior à do ambiente, devido a inércia térmica do equipamento. Os resultados são mostrados nas Figuras 5 e 6 .

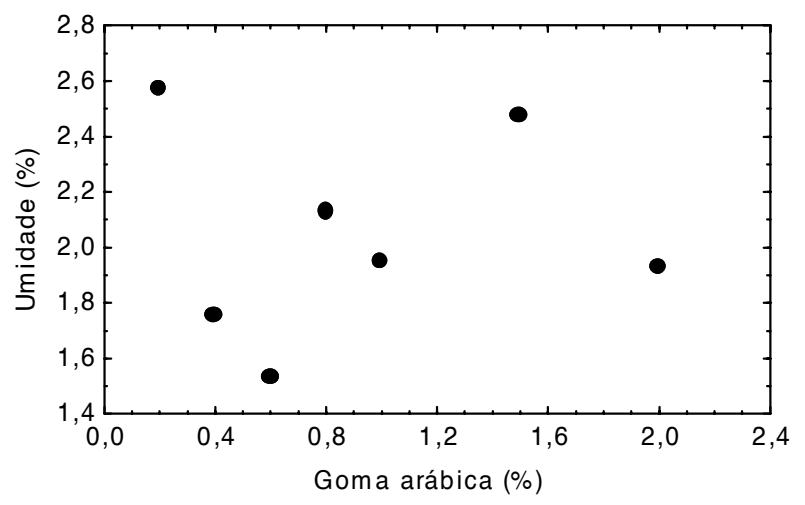

FIGURA 5. Massa de pó de erva-mate coletado

Ao diminuir o tempo de resfriamento do equipamento para o valor médio de 3,5 minutos, antes de se efetuar a retirada do pó, ocorreu diminuição do conteúdo de umidade do pó de erva-mate produzido. No experimento anterior, onde o tempo de resfriamento foi de $10 \mathrm{minu}-$ tos, a umidade do pó alcançou valores superiores a $6 \%$, e ao operar com menor tempo de esfriamento, a umidade foi inferior a 2,5\%. Esta análise mostra que a ervamate em pó, produzida, nas condições operacionais utilizadas, apresenta conteúdo de umidade compativel com o de produtos similares e que apresentam tempo de vida útil prolongado

\section{3 - Análise sensorial}

Análise sensorial foi utilizada para avaliar os produtos obtidos. O Teste de Ordenação foi utilizado para estabelecer atributos de intensidade de sabor. Este teste é amplamente utilizado devido a facilidade de aplicação e interpretação dos resultados. Várias amostras são distribuídas ao mesmo tempo e pede-se aos degustadores que as coloquem em ordem crescente ou decrescente da característica (atributo) que está sendo avaliado. O número de amostras irá depender da complexidade da amostra, da experiência dos provadores e da qualidade da mesma. Normalmente são utilizadas de 3 a 20 amostras. Números maiores de amostra são utilizados quando a equipe de provadores é experiente e treinada, do contrário utiliza-se de 3 a 10 amostras. Pode-se empregar também uma escala de pontuação. A interpretação dos resultados foi efetuada pela tabela de Fischer [11].

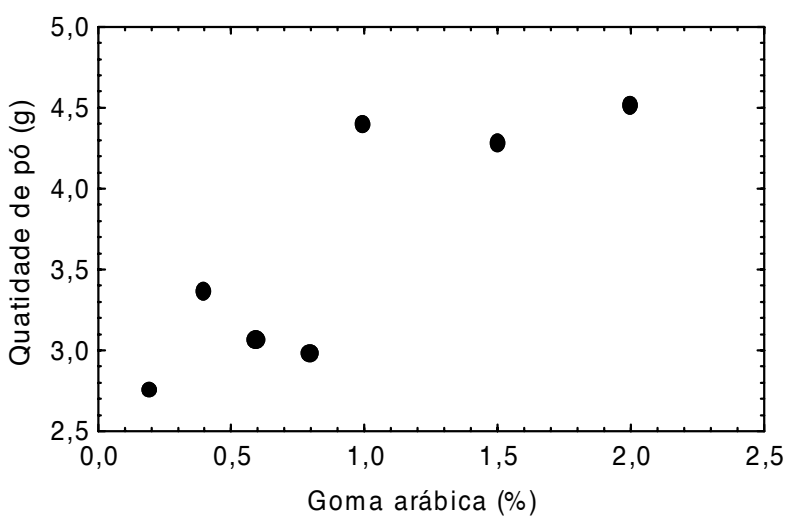

FIGURA 6. Umidade de pó de erva-mate coletado

TABELA 4. Análise sensorial do chá de erva-mate Cambona 4.

\begin{tabular}{llll}
\hline Provador & \multicolumn{3}{c}{ Amostra } \\
\hline 1 & $12 \mathrm{C}$ & $14 \mathrm{~B}$ & $16 \mathrm{D}$ \\
2 & 2 & 1 & 3 \\
3 & 3 & 2 & 1 \\
4 & 2 & 1 & 3 \\
5 & 3 & 1 & 2 \\
6 & 2 & 1 & 3 \\
7 & 3 & 1 & 2 \\
8 & 1 & 2 & 3 \\
9 & 3 & 1 & 2 \\
10 & 3 & 2 & 1 \\
11 & 2 & 1 & 3 \\
12 & 1 & 3 & 2 \\
13 & 1 & 2 & 3 \\
14 & 2 & 1 & 3 \\
15 & 2 & 1 & 3 \\
16 & 2 & 1 & 3 \\
Total & 3 & 2 & 1 \\
\hline
\end{tabular}

Testes sensoriais preliminares, utilizando provadores não treinados, indicaram que soluções contendo $0,1 \mathrm{~g}$ de pó dissolvidas em $10 \mathrm{~mL}$ de água apresentavam boa aceitabilidade. Foram analisadas três amostras de chá 
de erva-mate Cambona 4. Optou-se por uma amostra desprovida de goma arábica, outra com pequena percentagem de goma e outra com concentração de goma arábica mais elevada. Evitou-se testar sensorialmente, amostras com conteúdos próximos de aditivos, o que poderia afetar a sensibilidade dos provadores. As soluções foram preparadas contendo $0,1 \mathrm{~g}$ de pó de erva-mate diluídas em $10 \mathrm{~mL}$ de água. As amostras que foram analisadas continham: $0 \%, 0,2 \%$ e $1,0 \%$ de goma arábica. As três amostras foram avaliadas por uma equipe de 16 provadores não treinados. Cada provador recebeu aproximadamente $30 \mathrm{~mL}$ de chá de erva-mate (sem açúcar). Todas as amostras foram aquecidas em banho maria à temperatura constante de $50^{\circ} \mathrm{C}$.As amostras analisadas seguiram a legenda:

- Pó com $1 \%$ de goma arábica $=16 \mathrm{D}$

- $\quad$ Pó com 0,2\% de goma arábica = 14B

- Pó sem adição de goma arábica $=12 \mathrm{C}$

Os atributos analisados foram :1 = sabor mais intenso; 2 = sabor intermediário; 3 = sabor menos intenso. Os resultados da análise são mostrados na Tabela 4. Analisando os dados da Tabela 4 (Teste de Ordenação), verifica-se que a preferência, em teor de intensidade do sabor de erva-mate, foi pela amostra com 0,2 \% de goma arábica. Esta amostra apontou, segundo os provadores, maior intensidade de sabor de erva-mate que a amostra sem aditivo (12C). Isto sugere que o material encapsulado retém aromas de erva-mate. Quando se efetua a comparação entre as amostras de erva-mate com 0,2 e 1,0\% de goma arábica, pelo teste de Ordenação, verifica-se que a preferência em teores de intensidade do sabor da ervamate, foi pela amostra com $0,2 \%$ de goma arábica. Provavelmente, ao utilizar 1,0\% de goma arábica, há maior retenção de aromas, porém a maior concentração de goma deve ter influência no sabor do produto, mascarando uma provável retenção mais acentuada de aromas. Os dados foram avaliados por meio da Intrepretação de Fischer, cuja pontuação é dada por: $1=0,85 ; 2=0 ; 3=$ $-0,85$. O resultado é mostrado na Tabela 5.

Utilizando os resultados da Interpretação de Fischer, efetuou-se a Análise de Variância e os resultados são sintetizados na Tabela 6.

Relacionando os limites unilaterais de $\mathrm{F}$ ao nivel de $5 \%$ de probabilidade para o caso de $\mathrm{F}>1$; e utilizando o grau de liberdade da amostra, igual a 2 e o grau de liberdade do resíduo, igual a 30, obtém-se F tabelado a nivel de $5 \%$ de probabilidade, igual a 3,32. Para o nivel de $1 \%$ de probabilidade para o caso de $F>1$, tem-se $F$ tabelado igual a 5,39.

Para existir diferença significativa entre as amostras é necessário que o F calculado seja maior que o F tabelado. Então, existe diferença significativa entre as amostras ao nivel de $5 \%$ de probabilidade, pois $\mathrm{F}$ calculado > F tabelado; ou seja, 4,89 > 3,32.

Aplicou-se o teste de Tukey para identificar entre quais amostras há diferença significativa. Para tanto determinou-se valores de amplitude total estudentizada (q). Ao Nivel de 5\% de probabilidade, utilizando o núme- ro de tratamentos igual a 3 (três amostras), e o número de graus de liberdade do residuo igual a 30 , obtém-se $\mathrm{q}=3,48$ (tabelado). Calculando:

- $\Delta 5 \%=\mathrm{q} \cdot\left(\mathrm{QM}_{\text {residuo }} / \text { número de provadores }\right)^{1 / 2}$

- $\Delta 5 \%=3,48(0,58 / 16)^{1 / 2}=0,66$

Determinou-se a média das amostras:

- Média $12 \mathrm{C}=-2,55 / 16=-0,16$

- $\quad$ Média $14 \mathrm{~B}=7,65 / 16=0,48$

- Média $16 \mathrm{D}=-5,1 / 16=-0,32$

Diferença das médias

- Média $12 \mathrm{C}$ - média $14 \mathrm{~B}=-0,64$

- Média $12 \mathrm{C}$ - média $16 \mathrm{D}=0,159$

- Média $14 \mathrm{~B}$ - média $16 \mathrm{D}=0,8$

O valor encontrado da diferença das médias superior ao valor de $\Delta 5 \%$, indica haver diferença significativa entre as amostras.

TABELA 5. Interpretação de Fischer

\begin{tabular}{ccccc}
\hline Provador & \multicolumn{5}{c}{ Amostra } \\
\hline & $12 \mathrm{C}$ & $14 \mathrm{~B}$ & $16 \mathrm{D}$ & Total \\
1 & 0 & 0,85 & $-0,85$ & 0 \\
2 & $-0,85$ & 0 & 0,85 & 0 \\
3 & 0 & 0,85 & $-0,85$ & 0 \\
4 & $-0,85$ & 0,85 & 0 & 0 \\
5 & 0 & 0,85 & $-0,85$ & 0 \\
6 & $-0,85$ & 0,85 & 0 & 0 \\
7 & 0,85 & 0 & $-0,85$ & 0 \\
8 & $-0,85$ & 0,85 & 0 & 0 \\
9 & $-0,85$ & 0 & 0,85 & 0 \\
10 & 0 & 0,85 & $-0,85$ & 0 \\
11 & 0,85 & $-0,85$ & 0 & 0 \\
12 & 0,85 & 0 & $-0,85$ & 0 \\
13 & 0 & 0,85 & $-0,85$ & 0 \\
14 & 0 & 0,85 & $-0,85$ & 0 \\
15 & 0 & 0,85 & $-0,85$ & 0 \\
16 & $-0,85$ & 0 & 0,85 & 0 \\
Total & $-2,55$ & 7,65 & -5.1 & 0 \\
\hline
\end{tabular}

TABELA 6. Resultados da análise de variância

\begin{tabular}{lcccc}
\hline CV & GL & SQ & QM & F \\
\hline Amostra & 2 & 5,69 & 2,84 & 4,89 \\
Provador & 15 & 0 & 0 & \\
Resíduo & 30 & 17,43 & 0,58 & \\
Total & 47 & & & \\
\hline
\end{tabular}

CV, Causas de variância; GL, Grau de liberdade; SQ, Soma dos quadrados; QM, Quadrado médio; F, Fator de distribuição estatístico.

Nos cálculos efetuados para encontrar as diferenças das médias, o único valor encontrado superior ao $\Delta 5 \%=0,66 ;$ foi o valor de 0,8. Então as amostras $14 \mathrm{~B}$ e 
16D diferem na intensidade do sabor ao nivel de 5\% de probabilidade. As amostras 14B e 16D equivalem respectivamente a $0,2 \%$ e $1,0 \%$ de goma arábica adicionada no extrato de erva-mate.

Através da Tabela de Fischer é possivel observar que existe diferença sensorial entre as amostras de erva mate encapsuladas com 0,2\% e 1,0\% de goma arábica..

\section{4 - CONCLUSÕES}

Na extração de solúveis da erva-mate, obteve-se extratos com conteúdo de sólidos de aproximadamente 3\%. Quando a percentagem de goma arábica adicionada ao extrato varia de 0,2 para 0,8, a massa de pó coletada aumenta em cerca de $25 \%$. A massa de pó coletada aumentou com o aumento da concentração de goma arábica, o que deve estar relacionado com o aumento do tamanho das partículas formadas, pois a eficiência de coleta do ciclone é maior para partículas maiores. Ao processar misturas com maior teor de goma arábica obtevese produtos com maiores conteúdos de água. Diminuindo o tempo de resfriamento do equipamento de secagem, antes de se efetuar a descarga do pó, obtém-se produtos com menor conteúdos de umidade. Nos resultados da análise sensorial utilizando o Teste de Ordenação, verifica-se que a preferência por provadores, em termos de intensidade do sabor de erva-mate, foi pela amostra com 0,2 \% de goma arábica. Esta amostra apontou, segundo os provadores, maior intensidade de sabor de erva-mate. Isto sugere que o material encapsulado retém aromas de erva-mate. Quando se efetua a comparação entre as amostras de erva-mate com 0,2 e 1,0\% de goma arábica, pela Interpretação de Fischer, verifica-se que há diferença entre as amostras ao nivel de $5 \%$ de probabilidade

\section{5 - REFERÊNCIAS}

[1] BENINCÁ, C.; VALDUGA, A.t.; FINZER, J.R.D.; CAVALHEIRO, F. Equilíbrio sólido-líquido na extração de solúveis de erva-mate. Anais do II Congresso Sul-Americano da Erva-Mate. -Encantado. RS. pp. 329-332 2000 a.

[2] BENINCÁ, C.; VALDUGA, A.t.; FINZER, J.R.D.; CAVALHEIRO, F. Liofilização de extrato de erva-mate. Anais do II Congresso Sul-Americano da Erva-Mate. -Encantado. RS. pp. 333-336 2000b.
[3] BERTOLETTI, J. J. Relatório de impacto ambiental - RIMA, Usina Hidrelétrica Machadinho. Centrais Elétricas do Sul do Brasil S.A. 131p. 1987.

[4] CORREA, G. Sistema agroflorestal com erva-mate para reposição florestal da MAESA. Projeto Operativo. Comunicação Pessoal - Machadinho - RS. 2001.

[5] MARSTERS, K. Deposit-free spray drying: dream or reality. Proceedings of the $10^{\text {th }}$ International Drying Symposium (IDS'96) - Kraków. Poland. Vol A. pp 5260. 1996

[6].GRBAVCIC, Z.B.; ARSENIJEVIC, Z.A; ZDANSKI, F.K. Drying of suspensions in fluidized bed of inert particles. Proceedings of the $11^{\text {th }}$ International Drying Symposium (IDS'98). Halkidiki. Greece. Vol. C pp 20902097. 1998.

[7].KRÜGER, R.L., FINZER, J.R.D. VALDUGA, A.T. Sapeco e secagem de erva-mate (Ilex paraguariensis St Hil) em secador de bandeja vibrada. Anais do VII Seminário Instituicional de Iniciação Científica. Erechim-RS. pp. 219. 2001a.

[8].KRÜGER, R.L., FINZER, J.R.D. VALDUGA, A.T. Secagem de erva-mate (Ilex paraguariensis St Hil) em secador de bandeja vibrada. Anais do II Encontro de Iniciação Científica em Engenharia de Alimentos. Erechim-RS. pp. 23. $2001 \mathrm{~b}$.

[9].REINECCIUS, G.A. Carbohydrates for Flavor Encapsulation. Foody Technology, n.3, p. 144-146.1991

[10].SOUZA, D.R.; SILVA, M.F.; MURAKAMI, P.; FREITAS, T.P.S.; ANDRADE, V.F.; OLIVEIRA, W. P. Microencapsulaçao de óleo essêncial da casca da laranja usando leito de jorro: estudos preliminares. Anais do XXVII Congresso Brasileiro dos Sistemas Particulados - ENEMP - Campos do Jordão - São Paulo, 1999. p.633-638.

[11].TEIXEIRA, E.; MEINERT, E. M.; BARBETTA, P.A. Análise Sensorial de Alimentos. Florianópolis - UFSC, 1987, $187 \mathrm{p}$.

[12].VALDUGA, A. T.; BATTESTIN, V.; KRÜGER, R.L.; BENINCÁ, C.; FINZER, J.R.D. Técnicas e equilíbrio sólido-líquido no processamento de erva-mate. Ciência \& Engenharia, v. 10, n.2, p 69-78; 2001.

[13].VALDUGA, A.T.; BATTESTIN, V.; FINZER, J.R.D.; CAVALHEIRO, F. CICHOSKI, A. J. Utilização de liofilizado de extrato de erva-mate na fabricação de balas. Anais do II Congresso Sul-Americano da Erva-Mate. -Encantado. RS. pp. 362-365 2000.

[14].WANKENE, M. A. Carragenas, um ingrediente indispensável. Aditivos \& Ingredientes. Editora Insumos Ltda São Paulo. Número 6 (Janeiro/fevereiro): p. 23 - 31, 2000.

[15].WHISTLER, R.L.; DANIEL, J.R. Carbohidratos. In: FENNEMA, O.R. Química de los alimentos. Editorial Acribia S.A.Zaragoza p. 81 - 156. 1997. 